\title{
The concept of schizophrenia: pro et contra
}

\author{
ASSEN JABLENSKY
}

The year 1999 marks the centenary of the concept of schizophrenia which, as dementia praecox, was introduced by Emil Kraepelin in the sixth edition of the Textbook (Kraepelin, 1899) Within less than a decade, the diagnosis of dementia praecox became standard currency worldwide. Although certain modifications were made in the course of time, the essential characteristics of the concept did not undergo a mutation. The current ICD-10 and DSM-IV definitions and criteria of schizophrenia, which were designed to provide more rigorous standards for the diagnosis, appear to us as somewhat modernised (but less readable) versions of Kraepelin's original formulation.

In contrast to the apparent immutability of the diagnostic concept, research in schizophrenia and related disorders has in the past 20 years not only increased exponentially but taken a qualitatively new turn. New research technologies, ranging from molecular genetics to functional neuroimaging, have joined ranks with clinical research and epidemiology. Following on the footsteps of recent successes in the unravelling of the molecular basis of Huntington's disease (Gusella et al., 1983; Huntington's Disease Collaborative Research Group, 1993) and current work on Alzheimer's disease (Blacker \& Tanzi, 1998), new cohorts of investigators are tempted to believe that the discovery of the causes of schizophrenia is just around the corner. Yet no major breakthrough has yet occurred in key areas of schizophrenia research such as aetiology and risk factors, its genetic basis, and prevention. Some researchers and observers are beginning to feel very uncomfortable with the sense of stagnation in the field and voice the suspicion that the disease concept

Address for correspondence: Professor A. Jablensky, Department of Psychiatry and Behavioural Science, University of Western Australia, MRF Building, 50 Murray Street, Perth 6000 (Australia).

Fax: +61-8-9224.0285.

E-mail: assen@cyllene.uwa.edu.au of schizophrenia itself may be fundamentally flawed. Is schizophrenia a shared «scientific delusion» (Boyle, 1990)? Is it a construct supported by tradition and convention but devoid of demonstrable validity? Has the time not come to declare the bankruptcy of Kraepelinian nosology and to replace schizophrenia with something else (Sarbin, 1990)? Echoes of these concerns were again heard at the recent XI World Psychiatric Association Congress in Hamburg (6-11 August 1999). Although such iconoclastic views are shared by a minority, the questions are legitimate and should not be ignored.

Some influential disease concepts come on stage and then leave like "paradigms» that may be quietly abandoned, radically transformed, or explicitly rejected as part of the normal process of evoultion of medical nosologies (the history of psychiatry is replete with examples). The concept of schizophrenia, however, seems to stubbornly stick out. First, it has been the target of critique since its inception, and the arguments used by its earliest critics who disputed its validity are remarkably similar to those being advanced today. Secondly, notwithstanding the repeated attempts at its demolition, the disease concept of schizophrenia has survived many of its critics.

As early as 1912, Hoche (1912) argued that inferring a disease from the clinical manifestations of a syndrome is impossible and attacked Kraepelin for «chasing a phantom» in claiming a disease entity status for dementia praecox. In a similar vein, Jaspers (1948) referred to schizophrenia as "an idea in Kant's sense», i.e. a goal that could never be attained. Kraepelin himself, in his later work revised essential aspects of the concept by introducing a distinction between schizophrenic symptoms and the disease of dementia praecox. He proposed that: schizophrenic symptoms are by no means limited to dementia praecox ... the affective and schizophrenic forms of mental disorder do not represent the expression of particular pathological processes, but rather in- 
dicate the areas of our personality in which these processes unfold (Kraepelin, 1920). The subsequent conceptual history of schizophrenia represents, by and large, variations on the same theme. A distinguished biological psychiatrist observed that «after 30 years of modern schizophrenia research, not a single finding in schizophrenia has been unequivocally established as a marker of that disease», concluding that the search for the cause of schizophrenia was no different from the search for the Holy Grail (van Praag, 1993).

Recent research has highlighted further complications which raise questions about the current nosological concept of schizophrenia. In summary, these include:

\section{LACK OF SYMPTOMATOLOGICAL AND PROGNOSTIC SPECIFICITY}

The symptomatology of schizophrenia spans the entire spectrum of psychopathology and encompasses psychotic symptoms; affective symptoms (depression); neurotic symptoms (anxiety, obsessivecompulsive phenomena); organic symptoms (cognitive deficits, soft neurological signs, minor physical abnormalities); personality change (amotivational syndrome, apathico-aboulic states). The variation is evident both cross-sectionally and longitudinally. Attempts at structuring these protean manifestations by weighting (fundamental/accessory; first-rank/second rank); partitioning into dimensions (positive/negative, factor analysis); or applying a multiaxial classification have not been successful in reducing the variance and producing replicable results (McGorry et al., 1998). The «schizophrenic syndrome» appears to have no consistent and uniform description.

The course and outcome of schizophrenia are no less difficult to describe and predict. Follow-up studies have demonstrated that a significant proportion of patients meeting initial diagnostic criteria for schizophrenia recover. The proportions oscillate around $25 \%$ in the 5-year follow-up of the International Pilot Study of Schizophrenia, IPSS (Leff et al., 1992) and $22 \%$ in the 20 -year follow-up by $\mathrm{Hu}$ ber et al. (1980). At the other extreme, a comparable proportion of patients experience a progressively deteriorating chronic course. The majority exhibit a course which is intermediate between these two extremes. Attempts to identify predictors of course and outcome have only met with moderate success. The «best» predictors in the WHO studies, deter- mined by stepwise multiple regression analysis or logistic regression explained about $25 \%$ of the variance in course and outcome.

\section{THE BOUNDARY ARGUMENT}

Schizophrenia can be described as a fuzzy set of characteristics with poorly defined boundaries (Manton et al., 1994). Three diagnostic boundaries have attracted well justified interest. First, the delimitation from affective disorders: not only is there an overlap in the cross-sectional symptomatology but the longitudinal course of the two disorders shows a significant overlap or cross-over. In the IPSS, $17 \%$ of the patients who were rigorously diagnosed as schizophrenic, developed affective episodes in the subsequent course of their illnesses; a somewhat lower percentage $(8 \%)$ of patients initially diagnosed as manic exhibited a transition to persistent schizophrenic symptomatology in the course of the follow-up (Sheldrick et al., 1977). Secondly, the boundary to personality disorder: we are still at a loss to understand how schizotypal personality, socalled latent schizophrenia, and the subclinical formes frustes relate to the 'core' entity. Thirdly, the nosological status of the acute transient non-affective psychoses remains moot. In the absence of «points of rarity" between schizophrenia and these syndromes, proposed solutions such as a return to the «unitary psychosis» (Vliegen, 1980), or the drawing of boundaries by committee consensus are untenable.

\section{DO STANDARDIZED DIAGNOSTIC CRITERIA INCREASE HOMOGENEITY?}

DSM-III/IV and ICD-10 are based on a checklist approach and select patient samples that are homogeneous for severity, chronicity and disability. Both sets of criteria are relatively reliable. For example, the multi-centre trial of the ICD-10 criteria resulted in a kappa of 0.84 for all schizophrenic disorders; a similar result $(0.83)$ was obtained for the diagnosis of bipolar affective disorder (Sartorius et al., 1995). However, in any patient population which is sampled on the basis of ICD-10 or DSM-IIIR / DSM-IV criteria, we can expect that less severe, transient or atypical cases, as well as cases with missing data will be excluded. No evidence has been presented that patient samples identified by today's di- 
agnostic criteria are more valid with regard to the hypothetical entity of schizophrenia than samples diagnosed by the clinical 'pattern recognition' approach.

\section{NO ESTABLISHED DISEASE MARKER}

A large number of «candidate» biological markers have been proposed (Goldberg \& Gold, 1995; Falkai \& Bogerts, 1995; Owen \& Simpson, 1995), including (i) morphological features (left temporal horn enlargement; reduced asymmetry of planum temporale; reduced hippocampal volume; cell disarray in the CA 1-prosubiculum zone in the anterior hippocampus; reduced thalamus volume); pathophysiological dysfunction (oculomotor abnormalities; P50 gating); and neurochemical abnormalities (D2 receptor density; cortical cholinergic deficits; altered distribution of nicotinamide-adenine dinucleotide phosphate-diaphorase cells in the frontal lobe). None has been shown yet to satisfy the criteria for a disease marker. Biological measurements in schizophrenia are characterized by a wide range of variability and dispersion. Group means may mask underlying heterogeneity and the existence of discrete subtypes.

\section{GENETIC LINKAGE IS YET TO BE DEMONSTRATED}

Linkage studies in pedigrees with multiple cases of schizophrenia have resulted, at best, in the exclusion of about $1 / 3$ of the genome. More recent full genome scans have produced low positive lod scores over wide regions on chromosomes $1,6,8,11,13,15$, 18 and 22 , suggesting that multiple genes, each of a small effect, may be involved (Crow \& DeLisi, 1998). Doubt is increasing that the schizophrenia phenotype, as defined by current diagnostic criteria, can provide the resolution required for genetic analysis (Ginsburg et al., 1996).

Do these arguments carry sufficient weight to challenge and, eventually, cause the dismantling of the disease concept of schizophrenia? Having outlined arguments that challenge the validity of the concept of schizophrenia, we should now turn to the arguments suggesting that it may be premature to jettison the nosological concept of schizophrenia. A range of robust research findings indicate that in all of its variable manifestations schizophrenia does «behave» like a disease.

\section{THE INCIDENCE AND SYMPTOMS OF SCHIZOPHRENIA ARE SIMILAR IN DIFFERENT POPULATIONS}

The World Health Organization study (Jablensky et al., 1992), conducted in 13 geographical areas in Europe, the Indian subcontinent, West Africa, North and South America, and Japan, was the first cross-cultural epidemiological investigation in which standardized instruments and case-finding methods were applied to ascertain the first-contact incidence of schizophrenia in populations that differed widely in terms of demography, economy, culture, and general health. A total of 1379 cases were assessed at their first episode and reinterviewed at a 2-year follow-up. The age- and sex-specific incidence rates for «broadly» icd-9 diagnosed schizophrenia ranged from 0.16 per 1000 in Honolulu to 0.42 per 1000 in a rural area in India $(p<0.001)$. The rates for the «core» syndrome characterized by first-rank symptoms were in the range of 0.07 per 1000 (Aarhus, Denmark) to 0.14 per 1000 (Nottingham, UK), and the differences across sites were not significant. The conclusions of the who report emphasized the similarities of incidence and of clinical presentation of schizophrenia across populations. The occurrence of recognisable clinical forms of schizophrenia in indigenous and isolate populations (Mowry et al., 1994) adds further evidence to its universality.

The manifestations of schizophrenia have not changed significantly over time.

Direct evidence for this is provided by our re-analysis of Kraepelin's original research case summaries (Zählblätter) on all 187 cases of dementia praecox and manic-depressive insanity admitted to the University Psychiatric Clinic in Munich in 1908 (Jablensky et al., 1993). These cases were scored in terms of the Present State Examination syndrome checklist (Wing et al., 1974) and processed with the CATEGO algorithm to generate "present-day» ICD-9 diagnoses. The clinical features of these «archival» cases from 1908 were then compared with «modern» cases assessed in the WHO International Pilot Study of Schizophrenia, IPSS (WHO, 1979). The overall concordance between Kraepelin's original diagnoses and the computer-assigned ICD-9 diagnosis was $88.6 \%$, and the comparison between the most frequent symptoms of Kraepelin's dementia praecox cases and the IPSS schizophrenia cases indicated a substantial overlap. 
THE GENETIC EVIDENCE COLLECTED SINCE THE BEGINNING OF THE $20^{\text {th }}$ CENTURY IS REMARKABLY CONSISTENT

Family and twin studies, conducted since the formulation of the concept of dementia praecox and have resulted in remarkably consistent findings. Family and adoption studies have produced solid evidence of a strong genetic effect on the causation of the disorder and no evidence of a major effect of the early rearing environment (McGuffin et al., 1994). Monozygotic twin concordance is in the region of $50 \%$ while the concordance for dizygotic twins drops sharply to $10-15 \%$ which equals the morbidity risk for siblings sharing, on the average, half of their genes. Moreover, the recurrence risks within families are similar, if not identical, in different populations and cultures. Overall, the transmission pattern is non-Mendelian and strongly suggestive of a polygenic inheritance of the kind encountered in so-called complex diseases such as diabetes, asthma and ischaemic heart disease (Lander \& Schork, 1994).

\section{CONVERGING EVIDENCE OF A FUNDAMEN- TAL NEUROINTEGRATIVE DEFICIT}

Notwithstanding the variation and inconsistencies in many research findings, the overall picture emerging from neuropathological, brain imaging, neurophysiological and neurocognitive studies especially in the last two decades is one of a basic defect at the level of the multimodal cortical integration of sensory and associative inputs (Nestler, 1997; Feinberg \& Guazelli 1999). Functionally, this neurointegrative deficit is reflected in multiple measurable dysfunctions in sustained attention, inhibitory control and working memory. There is increasing evidence that the metaphor of «intrapsychic ataxia» used by Stransky (1904) to describe the inner world of the schizophrenic patient may indeed have a basis in a distinct pathophysiology that will ultimately be analysed in minute detail with the increasingly incisive research techniques available to neuroscience.

How can the contradictory sets of evidence concerning the nature of schizophrenia be reconciled? Proposals to abandon or dismantle the concept of schizophrenia because of its refractory and elusive nature are unrealistic. Attempts at discarding the notion of schizophrenia have been made in the past, without any constructive results. Similarly, renewed efforts to re-define its boundaries by reshuffling its symptoms and signs in the absence of a firm foundation in its neurobiology, are unlikely to contribute new knowledge. It would be premature to engage in grand theory building, although psychiatric thinking may be usefully informed by new concepts emerging in evolutionary biology, genetics and neuroscience.

First, we should recognize that in the area of schizophrenia and other psychotic disorders, we are dealing with complex phenotypes which do not fit the conventional biomedical model of disease. We must accept that epigenetic factors expressed in behaviour, subjective experience, and finely modulated responses to the environment form a dimension of the phenotype which cannot be reduced to the biomedical paradigm.

Secondly, the priority for the time being should be to introduce more methodological rigour into schizophrenia research. Examples of problems that need to be overcome include the small sample size and the insufficient statistical power in the majority of biological studies; the lack of epidemiological sampling strategies for biological and genetic research and the likely presence of a selection bias in much of the current research into the neurobiology of psychiatric disorders; the excessive reliance on categorical diagnoses such as provided by DSM-IIIR/DSMIV or ICD-10.

Whether schizophrenia is a disease, a syndrome arising as a 'final common pathway' for a variety of pathological processes, or a collection of symptoms and syndromes of multiple underlying causes, the concept has clinical and epidemiological validity and should not be abandoned unless a clearly superior alternative is proposed. Existing alternatives include: dimensional models derived from factor-analytical or latent class models (Kendler et al., 1998); the 'correlated phenotypes' approach specifying subtypes of schizophrenia according to the presence or absence of particular neurophysiological or neurocognitive abnormalities (Wickham \& Murray, 1997); and a differentiated clinical classification subdividing the psychoses into multiple, presumably more homogeneous clusters along the lines proposed by Leonhard (1957). While experimenting with such concepts may yield new insights in clinical research, a fragmentation of schizophrenia into subentities will result in reduced statistical power for epidemiological and genetic research. It is, therefore, desirable to retain the diagnostic concept of schizophrenia while refining it by using the above 
models as complementary, rather than alternative approaches. Notwithstanding the difficulties accompanying the genetic dissection of complex disorders, novel methods of genetic analysis will eventually identify genomic regions and loci predisposing to schizophrenia. The majority of them are likely to be of small effect, although the possibility that genes of moderate or even major effects also exist cannot be ruled out, especially with regard to the genetic basis of neurophysiological abnormalities contributing to the vulnerability to schizophrenia. Clarifying the function of such genes, of which many are likely to be common variants, will be a complex task. Part of the solution is likely to be found in epidemiology since establishing their population frequency and associations with a variety of phenotypic expressions, including personality traits and interactions with environmental risk factors, is a prerequisite for understanding their causal role. Thus, a molecular epidemiology of schizophrenia is likely to be the next major chapter in the search for its causes and cures.

\section{REFERENCES}

Blacker D. \& Tanzi R.E. (1998). The genetics of Alzheimer disease. Current status and future prospects. Archives of Neurology 55, 294-296.

Boyle M. (1990). Schizophrenia: a Scientific Delusion? Routledge: London.

Crow T.J. \& DeLisi L.E. (1998). The chromosome workshops at the $5^{\text {th }}$ International Congress of Psychiatric Genetics the weight of the evidence from genome scans. Psychiatric Genetics 8, 59-61.

Falkai P. \& Bogerts B. (1995). The neuropathology of schizophrenia. In Schizophrenia (ed. S.R. Hirsch and D.R. Weinberger), pp. 275-292. Blackwell: Oxford.

Feinberg I. \& Guazelli M. (1999). Schizophrenia: a disorder of the corollary discharge systems that integrate the motor systems of thought with the sensory systems of consciousness. British Journal of Psychiatry 174, 196-204.

Ginsburg B.E., Werick T.M., Escobar J.I., Kugelmass S., Treanor J.J. \& Wendtland L. (1996). Molecular genetics of psychopathologies: a search for simple answers to complex problems. Behavior Genetics 26, 325-333.

Goldberg T.E. \& Gold J.M. (1995). Neurocognitive deficits in schizophrenia. In Schizophrenia (ed. S.R. Hirsch and D.R. Weinberger), pp. 146-162. Blackwell: Oxford.

Gusella J.F., Wexler N.S., Conneally P.M., Naylor S.L., Anderson M.A., Tanzi R.E., Watkins P.C., Ottina K., Wallace M.R. \& Sakaguchi A.Y. (1983) A polymorphic marker limited to Huntington's disease. Nature 306, 234-238.

Hoche A. (1912). Die Bedeutung der Symptomkomplexe in der Psychiatrie. Zeitschrift für die gesamte Neurologie und Psychiatrie 12, 540-551

Huber G., Gross G., Schüttler R. \& Linz M. (1980). Longitudinal studies of schizophrenic patients. Schizophrenia Bulletin 6, 592605.

Huntington's Disease Collaborative Research Group (1993). A novel gene containing a trinucleotide repeat that is expanded and unstable on Huntington's disease chromosomes. Cell 72, $1-20$.

Jablensky A., Sartorius N., Ernberg G., Anker M., Korten A., Cooper J.E., Day R. \& Bertelsen A. (1992). Schizophrenia: Manifestations, Incidence and Course in Different Cultures. A World Health Organization Ten-country Study. Psychological Medicine Monograph Supplement 20, Cambridge University Press: Cambridge.

Jablensky A., Hugler H., von Cranach M. \& Kalinov K. (1993). Kraepelin revisited: a reassessment and statistical analysis of dementia praecox and manic-depressive insanity in 1908. Psychological Medicine 23, 843-858.

Jaspers K. (1948). Allgemeine Psychopathologie. Fünfte Auflage. Springer: Berlin. (English translation by J. Hoenig and M.W. Hamilton, General psychopathology, 1963, Manchester University Press \& The University of Chicago Press: Manchester \& Chicago).

Kendler K.S., Karkowski L.M. \& Walsh D. (1998). The structure of psychosis. Latent class analysis of probands from the Roscommon family study. Archives of General Psychiatry 55, 492-499.

Kraepelin E. (1899). Psychiatrie. Ein Lehrbuch für Studirende und Aerzte. Sechste, vollständig umgearbeitete Auflage. Barth: Leipzig.

Kraepelin E. (1920) Die Erscheinungsformen des Irreseins. Zeitschrift für die gesamte Neurologie und Psychiatrie 62, 1-29.

Lander E.S. \& Schork N.J. (1994). Genetic dissection of complex traits. Science 265, 2037-2048.

Leff J., Sartorius N., Jablensky A., Korten A. \& Ernberg G. (1992). The International Pilot Study of Schizophrenia: fiveyear follow-up findings. Psychological Medicine 22, 131-145.

Leonhard K. (1957). Aufteilung der endogenen Psychosen. Akademie-Verlag: Berlin. (English translation. by R. Berman, ed. by E. Robins, The Classification of Endogenous Psychoses, $5^{\text {th }}$ ed., 1979, Irvington \& Wiley: New York).

Manton K.G., Korten A., Woodbury M.A., Anker M. \& Jablensky A. (1994). Symptom profiles of psychiatric disorders based on graded disease classes: an illustration using data from the WHO International Pilot Study of Schizophrenia. Psychological Medicine 24, 133-144.

McGorry P.D., Bell R.C., Dudgeon P.L. \& Jackson H.J. (1998). The dimensional structure of first episode psychosis: an exploratory factor analysis. Psychological Medicine 28, 935-947.

McGuffin P., Owen M.J., O'Donovan M.C., Thapar A. \& Gottesman I.I. (1994). Seminars in Psychiatric Genetics. Gaskell: London.

Mowry B.J., Lennon D.P. \& De Felice C.N. (1994). Diagnosis of schizophrenia in a matched sample of Australian aborigines. Acta Psychiatrica Scandinavica 90, 337-341.

Nestler E.J. (1997). An emerging pathophysiology. Nature 385, 578-579.

Owen F. \& Simpson M.D.C. (1995). The neurochemistry of schizophrenia. In Schizophrenia (ed. S.R. Hirsch and D.R. Weinberger), pp. 358-378. Blackwell: Oxford.

Sarbin T.R. (1990). Towards the obsolescence of the schizophrenia hypothesis. Journal of Mind and Behavior 11, 259-284.

Sartorius N., Üstün T.B., Korten A., Cooper J.E. \& van Drimmelen J. (1995). Progress toward achieving a common language in psychiatry, II: Results from the international field trials of the 
ICD-10 Diagnostoc Criteria for Research for mental and behavioral disorders. American Journal of Psychiatry 152, 1427. 1437.

Sheldrick C., Jablensky A., Sartorius N. \& Shepherd M. (1977). Schizophrenia succeeded by affective illness: catamnestic study and statistical enquiry. Psychological Medicine 7, 619-624.

Stransky E. (1904). Zur Auffassung gewisser Symptome der Dementia praecox. Neurologisches Centralblatt 23, 1137-1143.

van Praag H.M. (1993). "Make-Believes" in Psychiatry or the Perils of Progress. Brunner \& Mazel: New York.
Vliegen J. (1980). Die Einheitspsychose. Geschichte und Problem. Enke: Stuttgart.

Wing J.K., Cooper J.E. \& Sartorius N. (1974). Measurement and classification of Psychiatric Symptoms. Cambridge University Press: Cambridge.

Wickham H. \& Murray R.M. (1997). Can biological markers identify endophenotypes predisposing to schizophrenia? International Review of Psychiatry 9, 355-364.

World Health Organization (1979). Schizophrenia. An International Follow-up Study. Wiley: Chichester. 